\title{
Rural Nursing Theory: Past, Present, and Future
}

\author{
Helen J. Lee and Charlene A. Winters
}

\section{DISCUSSION TOPICS}

- Discuss the strategies you might use to initiate and sustain theory development with your colleagues.

- Identify the areas within rural nursing theory (RNT) that need further development. Identify the specific strategies to address those needs.

- Identify the real-world learning experiences for students, which allow them to explore health needs and perceptions of rural persons from numerous rural groups.

\section{INTRODUCTION}

For this sixth edition of Rural Nursing: Concepts, Theory, and Practice, we believe it is important to take a step back and detail the history that led to the development of the theory. We also believe it is critical to provide direction to further its development. Therefore, the purpose of this chapter is to provide the (a) history, context, and assumptions; (b) current status and studies; and (c) future directions and needed research of the rural nursing theory (RNT). The historical content is divided into three phases.

\section{HISTORY, CONTEXT, AND ASSUMPTIONS}

Within the United States, the average population density is 87.4 persons per square mile (U.S. Census Bureau, 2019) and most persons live in cities. Most states contain rural areas, even New Jersey, where the population density is the highest in the United States at nearly 1,200 individuals per square mile. In contrast, based on 2017 U.S. Census Bureau estimates (Worldatlas, 2017), six states have fewer than 20 persons per square mile (Table 1.1). Montana ranks third in the population density list. 
TABLE 1.1 Least Densely Populated States in the United States

\begin{tabular}{llc}
\hline Rank & State & Persons/Square Mile \\
\hline 1 & Alaska & 1.3 \\
2 & Wyoming & 6.0 \\
3 & Montana & $6.8-7.1^{1}$ \\
4 & North Dakota & 11.0 \\
5 & South Dakota & 11.3 \\
6 & New Mexico & 17.2 \\
\hline
\end{tabular}

In 1975, Montana State University (MSU) recruited Anna M. Shannon, a native Montanan, to be the dean of the College of Nursing. Dr. Shannon was convinced that nursing practice in a rural environment was different from that in an urban place. Dr. Shannon also noted paucity in the numbers of articles pertaining to rural nursing in the literature base. The articles available were from sociology; the content examined the characteristics of young women entering the nursing profession.

\section{Phase 1 (1977-1998)}

Dean Shannon and two faculty members, Drs. Jacqueline Taylor (anthropologist) and Ruth Ludemann (sociologist) wrote federal grant applications to fund the rural generalist master's program beginning in 1977. MSU is a land grant university. The College of Nursing is a state-wide program; the main campus is located in Bozeman and at that time the extended campuses were located in Great Falls, Billings, Butte, and Missoula. Undergraduate students started their nursing courses in Bozeman and then transferred to the extended campuses for clinical courses. A four-quarter master's program was available at the Bozeman campus; students could enroll in adult, family-child, and psychiatric nursing.

Initially, the new graduate rural nursing program rotated around the College of Nursing's campus sites. The length of the program was five quarters. A thesis was required. For two of the rural core nursing courses, students were assigned to select a rural or remote community; in the first course, the community was to be described visually and structurally (population, governance, occupations, and healthcare availability). In the second course, titled Rural Nursing, the students interviewed 10 to 12 persons in the chosen community about their perceptions of their health and their healthcare. Course paperwork for both classes was reports of the findings of both activities. Participants were engaged primarily in the extractive industries-farming, ranching, and logging. Procedures for protection of human subjects were followed. ${ }^{2}$

In the spring of 1982, a podium presentation titled Sparsely Populated Areas: Towards Nursing Theory was given to the Western Council on Higher Education, a regional nursing research organization now called the Western Institute of Nursing (WIN). Introduced by College of Nursing Dean Shannon, the presentation's purpose was to demonstrate how a nursing school could "maximize its resources, provide opportunities for faculty and student research, and contribute ... to the development of an empirically based theory of nursing" (pp. 70-71). Dr. Taylor (1982) organized the presentation that included

1. Estimates may differ based on different data sources.

2. Community and interview data collection were supported in part by U.S. Department of Health and Services, Division of Nursing, Advanced Training Grant to Montana State University Grant (\#1816001649AI). 
faculty and graduate students' studies about the (a) role of distance in home dialysis, (b) sodium in drinking water and adolescent blood pressure, and (c) beliefs and practices of Crow Indian women, Hmong refugees, and Hutterite colony members. Her concluding remarks included a plan for theory construction and testing using retroduction, a process that includes both inductive and deductive reasoning.

Using the procedures described earlier, the faculty and student groups continued gathering data for the theory base using the student interviews, the community data they collected, and the student papers describing the health beliefs, values, and practices of the rural participants interviewed. Concepts emerging from the data included health status, health beliefs, isolation, distance, self-reliance, lack of anonymity, familiarity, insider/outsider, old timer/newcomer, and informal healthcare systems.

In 1983, Dr. Clarann Weinert developed a survey to validate the emerging concepts. Instruments used in the quantitative study and the constructs measured are listed in Table 1.2.

A convenience sample of 62 persons (40 women, 22 men) from 13 sparsely populated counties in Montana responded to the survey. The mean age of the sample was 61.3 years of age; the mean education year was 13.5 years. The survey data were analyzed to inform the qualitative data through the emerging concepts.

Rural Nursing: Developing the Theory Base, by Drs. Kathleen A. Long and Clarann Weinert, was published in 1989 (see a reprint of this paper in Chapter 2 in this text). The assumptions of the emerging theory guided the process: (a) Rural was defined as sparsely populated; the entire state of Montana was considered sparsely populated despite the population centers that existed within the state. (b) Healthcare needs of rural environments are different from healthcare needs in urban settings. (c) All rural areas have common needs. (d) Urban models of healthcare are not appropriate or adequate for rural areas.

Three theoretical statements were proposed. The first two statements pertain to rural persons. The first states that rural persons "define health primarily as the ability to work, to be productive and do usual tasks" (Long \& Weinert, 1989, p. 120). The second statement indicates that "rural persons are self-reliant and resist seeking help from those seen as 'outsiders' or from agencies seen as national or regional 'welfare' programs" (p. 120). A corollary to the second statement was that healthcare is usually sought through the informal rather than the formal system. The third statement applies to rural healthcare providers (HCPs): they "must deal with a lack of anonymity and much greater role diffusion than providers in urban or suburban settings" (p. 119).

Concepts related to the first statement include health beliefs, work beliefs, and healthseeking behavior. Isolation and distance were the two concepts that assisted in understanding health-seeking behavior of rural individuals. Despite living long distances from healthcare facilities, rural individuals did not view themselves as isolated.

Related to the second theoretical statement are the concepts of self-reliance and independence. The desire to care for oneself was common among the interviewed rural individuals.

TABLE 1.2 Survey Instruments and Constructs

General Health Perception Scale

Personal Resource Questionnaire

Trait Anxiety Scale

Beck Depression Inventory
Physical health status and health beliefs

(Davies \& Ware, 1981)

Informal systems for support and healthcare

(Brandt \& Weinert, 1981)

Mental health status (Spielberger et al., 1970)

Mental health status (Beck, 1967) 
Lack of anonymity is a major concept for the providers of nursing and healthcare in a rural environment. Closely associated with practice in a rural area are the related concepts of old-timer/newcomer and insider/outsider. These interrelated concepts guide rural individuals' interactions and relationships with nurses and other HCPs.

Following the publication of Long and Weinert's (1989) article about the RNT base (see a reprint of this paper in Chapter 2 in this text), several MSU faculty members committed to continue work on the theory. Enrolled graduate nursing students continued choosing and describing rural communities and interviewing their residents regarding their health perceptions. A concurrent activity began during this time; interested graduate students and nursing faculty began analyzing the concepts that emerged during the RNT process. Several students developed their community interviews into theses. These along with concept analyses papers became chapters in Conceptual Basis for Rural Nursing, a publication edited by Dr. Helen Lee (1998). ${ }^{3}$ The text ultimately became the first of the subsequent editions of Rural Nursing: Concepts, Theory, and Practice.

\section{Phase 2 (1999-2006)}

MSU College of Nursing faculty, Drs. Helen J. Lee and Charlene A. Winters, continued the theory work through the teaching of the rural nursing course in the graduate nursing curriculum. Presentations about the theory, the concepts, and the faculty-student collaboration were accepted at several Communicating Nursing Research Conferences sponsored by WIN, the Western regional nursing research organization (2001, 2002, and 2004).

During this time, three events led to the formation of a collaborative effort with nurse researchers in Canada. The first was an independent activity project and visit by Meg K. McDonagh from the University of Calgary to explore the emerging RNT work at MSU. The second and third events were the attendance of the core MSU faculty at two conferences, a Canadian Rural Conference in Saskatoon, Saskatchewan, Canada, and the Rural Nursing Research Conference in Binghamton, New York. The collaboration occurred with nurse researchers of the Faculty of Nursing, University of Calgary (Elizabeth H. Tomlinson, Meg K. McDonagh, Dana S. Edge, and Marlene A Reimer). Chad O'Lynn joined the MSU group of researchers. The work, titled North American Study (NAS) Group, led to the appointment of Dr. Winters as a visiting scholar at the University of Calgary Faculty of Nursing and a comparison study conducted across international borders about rural/ remote health beliefs between participants in Montana and the Canadian provinces of Alberta and Manitoba. The purposes of NAS were to (a) validate existing RNT concepts, (b) explore new emerging concepts, and (c) determine the areas for further theoretical development and research.

Following the activity of the comparison study group (Winters et al., 2016), the NAS group made these recommendations regarding RNT:

\section{Concepts}

a. Add identified new concepts to RNT: health-seeking behavior and choices (residence, HCP).

b. Most concept analyses were incomplete and the new concepts identified needed to be developed.

c. It was noted that validation of all the concepts was needed.

3. Funding sources for the publication of Conceptual Basis for Rural Nursing was a monetary grant received from the Montana Consortium for Excellence in Healthcare. The Consortium also funded, in part, the content of two chapters within the text. The grant award was facilitated by Jane E. Scharff. 
2. These issues arose during the analysis of the data and require further exploration as to their fit with RNT

a. Economic

b. Aging communities

c. Environmental exposure to chemicals, injury from animals, and safety with regard to driving and farm/ranch work injuries.

Dr. Helen Lee and Ms. McDonagh conducted an extensive review of literature that supported or refuted the RNT theoretical statements and concepts. They found that:

The rural residents' definition of health in the first descriptive statement is changing from that of a functional nature to a more holistic view that includes physical, mental, social, and spiritual aspects. The self-reliance of rural residents in the second relational statement is broadly supported; however, the resistance to seeking help from those seen as 'outsiders' is changing. The third relational statement pertaining to HCPs and their lack of anonymity and role diffusion is supported. The findings for the concept of distance in the original rural theory development work are not supported. This literature appraisal of the rural nursing theory base structure supports a need for change. (Lee E Winters, 2006, p. 24; also see Chapter 4 in this text)

At the end of this phase, Drs. Lee and Winters published the textbook, Rural Nursing: Concepts, Theory, and Practice (2006). The Springer Publishers considered it the second edition of Conceptual Basis for Rural Nursing. The change in title more accurately reflected the direction of the changing content of the book.

\section{Phase 3 (2007-2012)}

The NAS researchers determined that the third relational statement about rural nursing practice would be the next focus of the RNT research group. A study was designed to explore the degree to which nurses and health professionals working in rural and remote settings access and use health research in practice; it was called the Rural Nurse Research Access (RRA) study. The study was initiated with a pilot study in Montana to develop a questionnaire and was conducted in collaboration with graduate nursing students enrolled in the rural nursing course. The qualitative work consisted of a windshield survey of nine rural communities with populations of 3,000 or less and located 50 miles or more from an urban setting. The semistructured interviews were conducted by 29 rural nurses (age range 31-72; years in nursing 3-50; 11 were baccalaureate prepared and eight were associate degree graduates; 21 were employed in critical access hospitals [CAHs]). Verbatim transcripts and field notes were analyzed for common themes. The RRA qualitative findings from the pilot study showed that participants (a) equated the word research with gathering information, an activity that was done two to three times a day to two to three times a month, (b) considered research a workplace activity, (c) stated that their primary sources for health research information were colleagues (managers, staff nurses, and physicians), and (d) used the Internet, if available.

Based on the initial questionnaire findings from the pilot study, a comparative analysis was done with published studies in the literature and revisions were made. Subsequently, the finalized survey instrument was used in Canada to explore practices and attitudes with a mix of healthcare workers including nurses, physicians, and social workers.

Since the U.S. members of the RRA group wanted to focus their study on nurses, the survey was sent to registered nurses working in rural areas in three states-Montana, 
Oregon, and South Dakota. Human subject procedures were completed for the institutions involved in all three states. The names of participants were obtained through state boards of nursing files. Nurses working in rural counties (Rural-Urban Continuum Codes 6-9, U.S. Department of Agriculture, 2007) were the targeted recipients of the survey questionnaire. There was a response rate of $61 \%$ (Koessl et al., 2010).

The demographics of the RRA quantitative study participants were as follows:

- Their ages ranged from 41 to 60 years.

- Sixty percent had a university degree.

- Sixty percent were employed full time.

- Forty percent were employed in a hospital-based practice.

- More than $50 \%$ had been practicing for more than 20 years.

- Less than 50\% were practicing in a rural/remote setting.

- Sixty percent did not practice in the same community in which they lived.

The RRA study survey participants indicated that the evidence most frequently used was "a personal experience of caring for patients/clients over time" and "information that I learn about each patient/client as an individual," actions that are consistent with evidence-based practice (EBP; O'Lynn et al., 2009, p. 40; Melnyk et al., 2010). They ranked low-level evidence sources as most commonly used, and were least likely to use a research journal. When compared to Olade (2004), the survey participants were (a) more likely to have used research in the last year, (b) less likely to use more research if they could, and (c) unlikely to use research if it contradicted institutional policy or common sense. Their ability to evaluate research quality was lacking. The perception of practice as evidence-based was higher in younger nurses; $71.5 \%$ in nurses less than 30 years of age as compared to $22.2 \%$ in those 60 years of age and older (Koessl et al., 2010).

Members of the research team for this study were Helen Lee, Jean Shreffler-Grant, Charlene Winters, and Susan Luparell from MSU; Dana S. Edge, Meg McDonagh, Lianna Barnieh, and Elizabeth "Betty" Tomlinson from University of Calgary; Chad O'Lynn from the University of Portland; and Lori Hendrickx from South Dakota State University.

During this phase, Dr. Lee retired from teaching. The Rural Nursing: Concepts, Theory, and Practice, the third edition (2010) by Drs. Winters and Lee was published. This edition contained an update of the RNT from Dr. Lee and Ms. McDonagh to include clearly revised theoretical statements.

1. Rural residents define health as being able to do what they want to do; it is a way of life and a state of mind; there is a goal of maintaining balance in all aspects of their lives.

Older rural residents and those with ties to extractive industries are more likely to define health in a functional manner-to work, to be productive, and to do the usual tasks.

2. Rural residents are self-reliant and make decisions to seek care for illness, sickness, or injury depending on their self-assessment of the severity of their present health condition and of the resources needed and available. Rural residents with infants and children who experience illness, sickness, or injury will seek care more quickly than for themselves (Lee \& McDonagh, 2010, p. 27).

4. Funding sources for the phases of the RRA study included MSU College of Nursing grant, Sigma Theta Tau International, Zeta Upsilon Chapter (Montana state wide chapter), Sigma Theta Tau, Omicron Chapter (University of Portland), and South Dakota State University College of Nursing Intramural Funding. 


\section{Present Activity (2013-Present)}

Dr. Winters continued to teach the rural nursing course as previously described through 2013. After that time, the course was broadened to focus on vulnerable populations; however, rural remained a significant focus within the course. The fourth edition of Rural Nursing: Concepts, Theory, and Practice (Winters, 2013) was published with an increased number of international authors. The fourth and fifth editions (Winters \& Lee, 2018) expanded to include authors from across the United States. As with the previous editions, the focus was on explicating the concepts and propositions that guide nursing practice, rural healthcare delivery issues, and understanding the characteristics and behaviors of rural persons. Winters stated at a Community Forum for Nursing at South Dakota State University and Sanford USD Medical Center (2012) that:

What Drs. Long, Weinert, and Shannon knew is that research data, an understanding of context and resources, as well as rural perceptions of health and healthcare were critical to the provision of EBP. Together, these items constitute the available evidence that should drive rural clinical practice. The rural evidence base is in line with the American Nurses Association (ANA) and other nursing organizations mandate for our EBP interventions.

The American Nurses Association (ANA) standards of nursing practice and professional performance mandate the use of evidence-based interventions and the integration of research findings into practice (2004). EBP is a problem-solving approach to the delivery of healthcare that integrates the best evidence from well-designed studies and patient care data, and combines it with patient preferences and values, combined with clinical expertise (Melnyk et al., 2010). The Institute of Medicine maintained that EBP is a core competency that every healthcare clinician should have to meet the needs of the 21st-century healthcare system (Greiner \& Knebel, 2003). To achieve EBP as a core competency requires improved communication and collaboration, shared responsibility, synchrony of efforts, drawing close clinical research and practice, and an engaged public.

To facilitate rural research and practice (a) there must be an integration of rural experiences in nursing education, (b) nursing students must be recruited from rural settings, and (c) nursing education must be delivered from rural settings (Bushy \& Leipert, 2005). Strategies to integrate research and EBP projects require course assignments, collaboration with clinical partners on research applicable to clinical practice, and provision of networking and educational opportunities-academic/clinical partnerships (Miller et al., 2009).

Dr. Winters and her faculty colleagues have worked to increase collaboration efforts in western Montana. Groups, students (high school, undergraduate, and graduate), and faculty collaboration included the following:

- High school students and faculty collaboration: MSU researchers collaborated with a Libby Montana high school science teacher and students enrolled in a research elective on a community-based participatory research study conducted in Libby (Kuntz et al., 2009; Winters et al., 2008). The faculty presented a class on research process. Human subjects and research protocol training were provided. In the class, there was discussion and approval of a research proposal. A survey was developed and community-based data collection took place. Students were provided a report of the survey findings. Drs. Winters and Kuntz were the faculty mentors.

- Undergraduate nursing students and faculty collaboration: To explore community members' understanding of and interest in research, undergraduate MSU nursing students interviewed residents of Libby, Montana, as part of a community-based 
participatory research project (Winters et al., 2008). The interviews informed the research study and also served as an assignment in the students' senior-level community health nursing course. Dr. Kuntz was the faculty mentor.

- Undergraduate nursing students and faculty collaboration in a clinical course: To compare body mass index (BMI) of school children in Missoula, Montana, student teams used the compiled data in support of the Coordinated Approach to the Child Health program. Dr. Sandy Kuntz was the faculty mentor.

- Undergraduate nursing students and faculty collaboration in a research course: Students in Missoula, Montana, collaborated with hospital nurses and a faculty mentor to test whether hospital procedures for nasogastric tube placement and chest tube dressing changes were evidence based. Dr. Dorothy (Dale) Mayer was the faculty mentor.

- Graduate nursing students and faculty collaboration: Students conducted a secondary analysis of previously collected qualitative data to explore the rural context and women's self-management of chronic health conditions. Dr. Winters was the faculty mentor.

- Graduate nursing students and faculty collaboration: Students enrolled in a vulnerable population course selected a rural community, vulnerable subpopulation, and health-related issue to explore throughout the semester from the individual, provider, and health system perspective. Students searched and appraised the literature, conducted community and systems assessments, and interviewed individuals as part of the learning experience. Dr. Winters was the faculty mentor.

From each of these experiences, students and faculty learn valuable information about rural communities and rural persons that inform RNT, practice, and research. ${ }^{5}$

\section{FUTURE DIRECTIONS}

The collaborative work of MSU faculty in the above-mentioned EBP activities represents brief examples of the total number of activities occurring in the MSU College of Nursing. The examples with undergraduate students originated from one College of Nursing campus in western Montana. Collaboration with faculty members from other campuses in the MSU College of Nursing system would be ideal. Reinstating the RNT work group that existed in earlier years to conduct secondary analyses of qualitative data collected by graduate nursing students enrolled in the vulnerable populations course would provide valuable insight into current rural health issues. MSU is collecting funds to support an endowed research chair within the College of Nursing. When that goal is finally realized, may the rich heritage of this work on RNT be a stepping-stone for future work!

As indicated earlier, toward the conclusion of the comparative analysis across borders study, the NAS investigators identified a blueprint of work that was needed related to RNT development:

- Develop and test instruments to measure the concepts.

- Test the theoretical and relational statements.

5. Funding sources for the phases of the RRA study included MSU College of Nursing grant, Sigma Theta Tau International, Zeta Upsilon Chapter (Montana state wide chapter), Sigma Theta Tau, Omicron Chapter (University of Portland), and South Dakota State University College of Nursing Intramural Funding. 
- Compare and contrast the health perceptions and needs of persons living in differing rural cultures and environments:

- American Indians and Aboriginal peoples.

- Rural and remote persons in other areas in the United States, Canada, and elsewhere

- Urban, former urban, and other rural subpopulations

- Compare and contrast the health perceptions and needs of persons of differing circumstances:

- Ill and well populations

- Old-timers and newcomers

- Young and old

- The urban poor

- Target research on the third relational statement:

- Effect of technology on generalist role, role diffusion, and professional isolation.

- Explore gender differences.

The NAS group generated the following research questions:

1. Are the health-seeking behaviors identified unique to rural residents?

2. How do health-seeking behaviors differ from those of health promotion?

3. How do illness variables affect rural persons' health-seeking behaviors? Choice of $\mathrm{HCP}$ ?

4. What variables affect rural persons' acceptance of "outside" services/HCP?

5. Do various rural groups define health differently?

The above-mentioned needs and questions are still relevant for the RNT work that needs to be done today.

\section{CONCLUSION}

More than 40 years have passed since the initial work on RNT began. The RNT base as published is in need of revision. Advances in health service and communication technologies, healthcare practices, along with changes in the perceptions and behaviors of rural residents over the past four decades may account for the emerging concepts identified. The work identified and the generation of additional theoretical statements will increase the potential of generating a middle range theory pertaining to the healthcare of rural persons. Relevance of rural nursing will likely be measured by the ability to evolve and change as new knowledge shapes it.

\section{REFERENCES}

American Nurses Association. (2004). Scope and standards of practice. Author.

Beck, A. (1967). Depression: Causes and treatment. University of Pennsylvania Press.

Brandt, P., \& Weinert, C. (1981). The PRQ: A social support measure. Nursing Research, 30, 277-280.

Bushy, A., \& Leipert, B. (2005). Factors that influence students in choosing rural nursing practice: A pilot study. Rural and Remote Health, 5, 387. http:/ / rrh.deakin.edu.au

Davies, A., \& Ware, J. (1981). Measuring health perceptions in the health insurance experiment. RAND. 
Greiner, A. C., \& Knebel, E.(Eds.). (2003). Health professions education: A bridge to quality. National Academies Press. http://www.nap.edu/catalog/10681.html

Koessl, B. D., Winters, C. A., Lee, H. J., \& Hendrickx, L. (2010). Rural nurses' attitudes and beliefs toward evidence-based practice. In C. A. Winters \& H. J. Lee (Eds.), Rural nursing: Concepts, theory, and practice (3th ed., pp. 327-344). Springer Publishing Company.

Kuntz, S. W., Winters, C. A., Hill, W., Weinert, C., Rowse, K., Hernandez, T., \& Black, B. (2009). Rural public health policy models to address an evolving environmental asbestos disaster. Public Health Nursing, 26(1), 70-78. https:/ / doi-org.proxybz.lib.montana.edu/10.1111/j.1525-1446.2008.00755.x

Lee, H. J. (Ed.). (1998). Conceptual basis for rural nursing. Springer Publishing Company.

Lee, H. J., \& McDonagh, M. K. (2010). Updating the rural nursing theory base. In C. A. Winters \& H. J. Lee (Eds.), Rural nursing: Concepts, theory, and practice (3rd ed., pp. 19-39). Springer Publishing Company.

Lee, H. J., \& Winters, C. A. (Eds.). (2006). Rural nursing: Concepts, theory, and practice (2nd ed.). Springer Publishing Company.

Long, K. A., \& Weinert, C. (1989). Rural nursing: Developing the theory base. Scholarly Inquiry for Nursing Practice: An International Journal, 3, 113-127.

Melnyk, B. M., Fineout-Overholt, E., Stillwell, S. B., \& Williamson, K. M. (2010). The seven steps of evidence-based practice. American Journal of Nursing, 110(1), 51-53. https://doi.org/10.1097/01 .NAJ.0000366056.06605.d2

Miller, J., Bryant MacLean, L., Coward, P., \& Broemeling, A. M. (2009). Developing strategies to enhance health capacity in a predominantly rural Canadian health authority. Rural and Remote Health, 9, 1266. https://doi.org/10.22605/RRH1266

Olade, P. (2004). Evidence-based practice and research utilization activities among rural nurses. Journal of Nursing Scholarship, 36(3), 220-225. https://doi-org.proxybz.lib.montana.edu/ 10.1111/j.1547-5069.2004.04041.x

O'Lynn, C., Luparell, S., Winters, C. A., Shreffler-Grant, J., Lee, H. J., \& Hendrickx, L. (2009). Rural nurses' research use. Online Journal of Rural Nursing and Health Care, 9(1), 34-45. https://doi .org/10.14574/ojrnhc.v9i1.103

Shannon, A. (1982). Introduction: Nursing in sparsely populated areas. In J. Taylor, Sparsely populated areas: Toward nursing theory. Western Journal of Nursing Research, 4(3), 70-71.

Spielberger, C., Gorsuch, R., \& Lushene, R. (1970). STAI manual for the State-Trait Anxiety Questionnaire. Consulting Psychologist.

Taylor, J. (1982). Sparsely populated areas: Toward nursing theory. Western Journal of Nursing Research, $4(3), 69-77$.

U.S. Census Bureau. (2019). Quick facts: Montana. https://www.census.gov/quickfacts/table/ PST045216/30,00

U.S. Department of Agriculture Economic Research Service. (2007). Rural-urban continuum codes. https:/ / www.ers.usda.gov/data-products/rural-urban-continuum-codes

Winters, C. A. (2012, April). Rural nursing theory \& nursing research: Developing evidence-based care for rural dwellers. Presentation at a Community Forum for Nursing, South Dakota State University \& Sanford USD Medical Center, Sioux Falls, SD.

Winters, C. A. (Ed.). (2013). Rural nursing: Concepts, theory, and practice (4th ed.). Springer Publishing Company.

Winters, C. A., Kuntz, S. W., Weinert, C., \& Rowse, K. (2008). Exploring research communication E engagement in a rural community: The Libby Partnership Initiative. National Institutes of Health/National Institute of Nursing Research. [1R03NR011242-01].

Winters, C. A., \& Lee, H. J. (2018). Rural nursing: Concepts, theory, and practice (5th ed.). Springer Publishing Company.

Winters, C. A., \& Lee, H. J. (Eds.). (2010). Rural nursing: Concepts, theory, and practice (3th ed.). Springer Publishing Company.

Winters, C. A., Thomlinson, E. H., O’Lynn, C., Lee, H. L., McDonagh, M. K., Edge, D. S., \& Reimer, M. A. (2006). Exploring rural nursing across borders. In H. J. Lee \& C. A. Winters (Eds.), Rural nursing: Concepts, theory and practice (2nd ed., pp. 27-39). Springer Publishing Company.

Worldatlas. (2017). Least densely populated U.S. states. http:/ / www.worldatlas.com/articles/least-densely-populated-u-s-states.html 